\title{
An Evaluation of a Community- Based, Integrated Crisis-Case Management Service
}

\author{
Terry Krupa and Heather Stuart \\ Queen's University \\ Alan Mathany \\ Frontenac Community Mental Health Services \\ Jennifer Smart and Shu Ping Chen \\ Queen's University
}

\begin{abstract}
This study presents findings of an evaluation of a community-based crisis service that used systems enhancement funding to modify services. In addition to developing timelier crisis services and increasing mobile capacity, the service adaptations focused on broadening the scope of the crisis service and addressing the follow-up needs of individuals served. While service development was guided by the research and best practice literature, there was little guidance available on how to address the latter two goals. The development of a transitional case management model integrated with crisis services was an innovation in service delivery. The evaluation used existing databases to compare crisis service delivery between two distinct periods (i.e., "old model" vs. "new model"). Study findings suggest that the new model did lead to the expected changes in service utilization patterns, specifically to increased service capacity, greater access to mobile crisis services, improved access to a broader community population, and more appropriate patterns of service delivery with respect to fewer days of crisis service and exit dispositions more consistent with crisis resolution. Rankings of acceptance of the new crisis service by the local service network varied greatly across service sectors, suggesting the need for more strategic community outreach efforts. The findings indicate that policy and funding opportunities within the mental health system need to be flexible and sensitive enough to address emerging issues in the field and to facilitate service innovations.
\end{abstract}

Terry Krupa, School of Rehabilitation Therapy, Queen's University, Kingston; Heather Stuart, Community Health and Epidemiology, Queen's University, Kingston; Alan Mathany, Director of Clinical Services, Frontenac Community Mental Health Services, Kingston; Jennifer Smart, PhD student, School of Rehabilitation Therapy, Queen's University, Kingston; Shu Ping Chen, PhD candidate, School of Rehabilitation Therapy, Queen's University, Kingston.

Funding for the research was provided by the Ontario Ministry of Health and Long-Term Care through the Ontario Mental Health Foundation, Systems Enhancement Evaluation Initiative. Thanks are extended to the service providers who participated in this evaluation.

Correspondence concerning this article should be addressed to Terry Krupa, Queen's University, 31 George Street, Kingston, ON K7L 3N6. Email: terry.krupa@queensu.ca 
A crisis of mental health is a response to daily life events that overwhelm an individual's coping capacities and adaptive behaviours and is experienced as a distressing mental and emotional disequilibrium (Aguilera, 1998). Crisis intervention services are delivered as specialty services that provide an immediate response to help a person stabilize and resolve the crisis experience. The availability of a crisis response capacity has become widely regarded as an important component of a comprehensive mental health system in Canada (Bilsker et al., 2002; Health Systems Research Unit, 1997).

Community-based crisis services have developed within the context of the overall shift from hospital to community-based mental health services. Crisis services have traditionally been offered through hospital emergency rooms, an emotionally intense and frequently chaotic treatment environment that is inconsistent with the mental health stabilization needs of individuals in crisis (Lauer \& Brownstein, 2008). Recent discussions about the extent to which stigma and discrimination related to mental illness is demonstrated in emergency rooms have contributed to the relevance of specialty community-based mental health crisis service delivery (Sartorius, 2002). Providing crisis services in the community has the potential to deal with the crisis situation directly within the natural context, to increase access to crisis services for people and situations that have been typically "hard to reach" within the mental health system, and to divert people from institutional care, including both hospitals and jails (Ferris, De Siato, Sandercock, Williams, \& Shulman, 2003; Ligon, 2005).

Community crisis services have been conceptualized as a system response to both individuals and situations. These services aim to meet the crisis needs of people with serious mental illness living in the community to reduce hospital use, involuntary treatment, and criminalization (Bonnie, Reinhard, Hamilton, \& McGarvey, 2009; Joy, Adams, \& Rice, 2006), and to address a broad range of difficult crisis situations in the community related to substance use, domestic violence, the mental health of adolescents, and traumarelated stress (Brown, 2005). In addition, current conceptualizations stress that as part of a service system striving to be recovery-oriented, crisis services should be offered in a manner that recognizes and builds individual coping strengths, potential for growth, and community contributions (Mental Health Commission of Canada, 2009). The rising complexity and dynamic nature of crisis situations emerging in communities and shifts in the philosophical ideals for crisis response require crisis services to have considerable structural and organizational adaptability.

This paper describes the evaluation of changes made by a community-based crisis service located in a small city in southeastern Ontario to address emerging community needs. This crisis service used provincial system enhancement funding to design and extend services to address several concerns. First, the service was experiencing challenges in offering timely and direct responses to community crisis needs on a 24/7 basis. Second, the service was limited in its ability to offer mobile responses, a critical element of a comprehensive crisis response system (Ontario Ministry of Health and Long-Term Care, 2005). Third, there were concerns that while crisis services were being accessed by individuals who had serious mental illness and by those with a history of receiving inpatient mental health services, they were not effectively addressing the broader range of community crisis needs. Finally, the lack of available follow-up services was creating a "bottleneck" that constrained the ability to meet new crisis needs as they emerged.

While there was considerable research available related to the organization of crisis services to ensure timely service delivery and mobile capacity, there was relatively little guidance in the research literature on how to effectively organize crisis services both to expand the scope of the crisis service and to improve 
access to follow-up services. This led to the innovation of the integrated crisis-case management service that is the focus of this evaluation study.

\section{BACKGROUND}

Best practice in community crisis response systems includes a range of elements integrated across providers and services, addressing both crisis-specific functions and also pre-crisis and ongoing support functions (Public Health Agency of Canada, 2002). Elements that are particularly relevant for community crisis services include 24-hour telephone crisis response, walk-in crisis services, and the provision of mobile response. This latter capacity for mobile response has received considerable attention and has been widely instituted. Geller, Fisher, and McDermeit (1995) conducted a national survey of mobile crisis services in the United States and categorized the reported benefits of these services into (a) advantages experienced by service recipients and their families, such as early intervention in the natural setting; (b) advantages to service providers, such as improved relations with community agencies, and (c) advantages to the mental health system, such as reduced hospital admissions. However, the survey indicated considerable variation in both the delivery and structure of mobile crisis services.

Published evaluation studies of mobile crisis services are sparse, but those that do exist suggest that these services are favourably received by service recipients and their families, and that they have a positive impact on hospitalization rates, both compared to crises managed in hospital settings and those managed by police (Guo, Biegel, Johnsen, \& Dyches, 2001; Joy et al., 2006; Scott, 2000). The recognition that law enforcement services are key providers in the response to community crises has led to the evolution of several distinct models for the collaboration between mobile crisis teams and local police departments (Lamb, Weinberger, \& DeCuir, 2002).

Issues related to the need for follow-up services for those who experience a crisis have not been the subject of much discussion in the literature. By definition, crisis services are designed to address crisis situations that can be stabilized in the short-term. When issues are likely to be ongoing, leaving individuals vulnerable to further crises, the crisis service makes referrals to other community services. Length of service time is not routinely reported or discussed, with a notable exception being England's Crisis Resolution Teams that specify care as typically lasting no more than 6 weeks (Johnson, 2004). The lack of attention to length of service further complicates evaluation in the field. A systematic review of crisis intervention by Joy and colleagues (2006) found that services often extend beyond the acute crisis situation, confounding

the evaluation of crisis interventions and blurring the distinction between crisis services and other forms of community care.

Individuals who are returning to the community after receiving inpatient mental health treatment have been recognized as a high-risk group for experiencing a broad range of crisis situations associated with recidivism. Brief, critical time interventions for this group of individuals have been recommended to help bridge inpatient and community life, and evaluations of these interventions have demonstrated effectiveness in supporting stability and well-being in community life (Dixon et al., 2009). While conceptualized as distinct, this type of service does appear to be a promising complement to crisis services by proactively preventing the emergence of crisis experiences and incidents during the transition to community life. 


\section{METHOD}

The present study evaluated the extent to which the new integrated crisis-case management service led to expected and desired changes in service delivery patterns. Specifically, it investigated the relationship between this new crisis service model and (a) service capacity, (b) access to mobile crisis service, (c) access to crisis services by the broader community, (d) appropriateness of service delivery patterns, and (e) acceptability of the new crisis service to the local network of community mental health and social services.

We used a non-equivalent group design to compare 1 year of service delivery in the old crisis model (any crisis contact between November 1, 2004, and October 31, 2005) with that offered by the new integrated crisis-case management model (any crisis contact between March 1, 2006, and February 28, 2007). The evaluation of acceptance by the local community service network was limited to the new model only. The study received ethics approval from the Queen's University Research Ethics Board. The evaluation was conducted by researchers from a local university in close collaboration with staff of the parent mental health agency and the crisis service itself.

\section{Program Descriptions}

Data collection included interviews with staff of both the crisis and the transitional case management programs to develop an accurate description of key service elements, refinements, and innovations. In addition, we collected information about the actual implementation of the service following enhancement funding to inform our interpretation of findings.

The crisis and transitional case management services are offered by Frontenac Community Mental Health Services, a multiservice community-based agency. The agency also offers housing, vocational services, case management, and assertive community treatment. The vision and mission of the parent organization are closely aligned with recovery values and ideals.

Figure 1 offers a diagrammatic representation of the key elements of the new and old crisis services. Enhancement funding was used to

- integrate the after-hours crisis calls directly with the crisis service and to extend the hours of operation;

- enhance the capacity for mobile responses and extend the expectations of this mobile service to include regular visits into the community, with a view to preventing crises, raising the profile of the service in the broader community (for example with local businesses), and addressing mental health crisis issues in collaboration with community service partners. This included, for example, regular visits to local shelters and the development of collaborations with local police; and

- implement a transitional case management program (TCM) to address clinical and psychosocial issues requiring a longer period of support than can be offered within a short-term crisis service, and to address the transition needs of individuals returning to the community following a mental health inpatient hospitalization. The TCM was designed to serve up to 60 clients for $8-10$ weeks. It would receive referrals directly from the crisis service and also from local inpatient settings. 


\section{Figure 1}

Service Changes: Models of Service Before and After Funding Enhancements

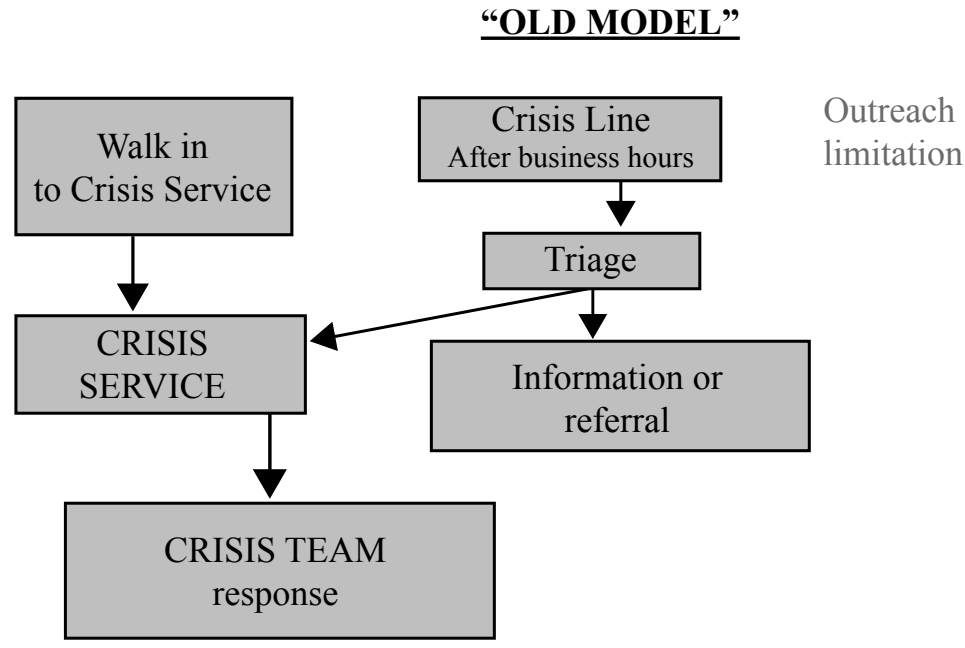

Limited mobile crisis response

No built-in follow-up

\section{"NEW MODEL"}

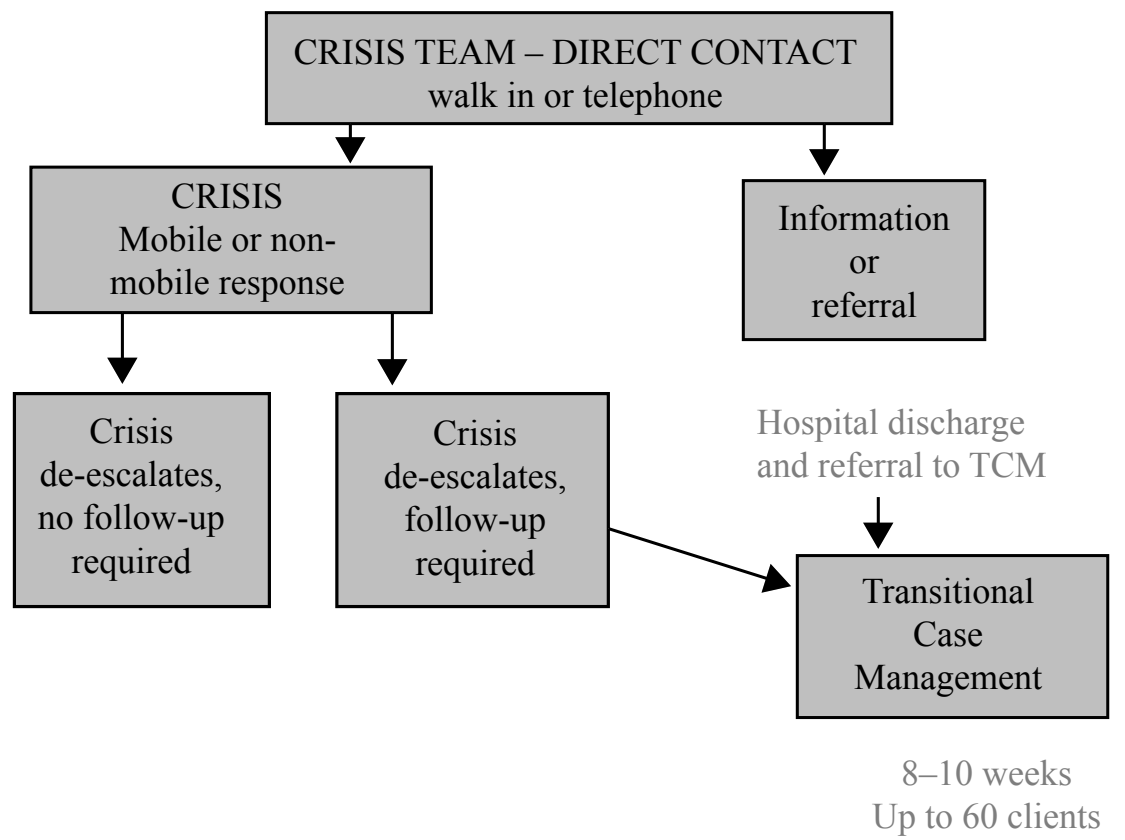

Note. $\mathrm{TCM}=$ transitional case management. 


\section{Data Collection}

Data about social-demographics, clinical variables and presenting issues, and service utilization patterns were collected through the existing databases of information routinely collected by the service and its larger parent organization. These included data from the Client Record Management System (CRMS) and Crisis Service Module Logs. In addition, data about hospitalization and emergency room use were collected through a local hospital records linkage system. All data were examined, cleaned, and finally entered into a new study database. Data were excluded when there had been major changes to data collection rules or processes over the study periods, or when the number of "unknowns" for any data variable reached $20 \%$ or higher.

To understand the acceptability of the new model of crisis service to the local network of community mental health and social services, we developed a new survey questionnaire based on the Balanced Scorecard Framework (Kaplan \& Norton, 1996), a strategic planning and performance measurement designed to give managers a "balanced" view of organizational performance. For this study, we adapted three perspectives from the Balanced Scorecard to create a survey that asked community partners to rate the remodelled crisis service as to its perceived helpfulness (11 questions) and perceived efficiency (7 questions). Finally, 5 questions evaluated the extent to which community partners understood the new model and asked them to rate their own capacity to manage crises. The survey included an overall rating of satisfaction with the service. The survey used a Likert scale response format ranging from 1 (strongly disagree) to 5 (strongly agree). Since the survey questionnaire was newly created and not available to evaluate satisfaction during the delivery of the old service model, ratings of the extent to which key elements of the service were perceived to be improved, the same, or worse were included. In addition, survey respondents were provided the opportunity for open-ended comments about their impressions and recommendations for the service.

An effort was made to identify all local public agencies and associations who would have an interest in the changes made to the crisis services. Fifty-four local agencies were identified and asked to participate through a letter of invitation and a follow-up letter. Representatives with some supervisory or management experience who had a broad knowledge of the work of the agency were targeted for recruitment. Surveys could be completed online, or if requested a hard copy was sent to the agency. Surveys were completed in a 6 -week period in early 2008 .

\section{Data Analysis}

Data was analyzed using SPSS version 16. Significance levels were set at $p<.05$. Analysis of categorical data included calculation of frequency counts and proportions, while means and standard deviations were calculated for continuous data. For some variables, data were collapsed into new categories to manage small counts or to enhance the meaningfulness of the data. Analysis included the use of descriptive statistics to compare the two study groups on variables of interest and calculations of percentage change. Simple descriptive statistics were used to calculate the community ratings of the service, and open-ended questions were analyzed using a simple content analysis. 


\section{RESULTS}

\section{Service Capacity and Characteristics of Population Served by the Crisis Service}

The new model demonstrated a significant increase in the number of unique individuals served over the study time period (old model: $n=108$; new model: $n=216$ ). Comparisons of the populations served by the two models indicated that there were no significant differences between the groups in age, gender, marital status, residential status, legal status, principal income, or diagnosis. Notable differences between the groups served existed for employment status, living arrangements, and hospitalization use. In the new model, $24 \%$ of the individuals served were likely to be employed, while only $14 \%$ of those served by the old model were employed. Differences in living arrangements approached significance with those served by the new model more likely to be living alone or with a relative, and those served in the old model more likely to be living with non-relatives. Individuals served by the old model experienced significantly more emergency room visits, more hospital admissions, and more days in hospital in the 6 months prior to receiving crisis services (see Table 1).

Table 1

Comparison of Hospital Service Utilization Patterns for the Period 6 Months Prior to Receiving Crisis Services

\begin{tabular}{lcc}
\hline Use of hospital services & $\begin{array}{c}\text { Old model } \\
\text { Mean/SD }\end{array}$ & $\begin{array}{c}\text { New model } \\
\text { Mean/SD }\end{array}$ \\
\hline Days in hospital 6 months prior* & $8.31 / 16.32$ & $0.81 / 4.35$ \\
Number of hospital admissions* & $0.75 / 1.37$ & $0.14 / 0.49$ \\
Number of emergency room visits* & $0.58 / 1.2$ & $0.12 / 0.47$ \\
\hline
\end{tabular}

Note. ${ }^{*} p<.001$.

\section{Delivery of Mobile Crisis Response}

As expected, the new model demonstrated a dramatic increase in the number of mobile crisis visits provided (old model number of mobile visits $=1$; new model $=72$ ).

\section{Access to Crisis Services}

The new model demonstrated referral source patterns reflecting a range of pathways to crisis services within the broader community. The new model of crisis service was significantly more likely to receive referrals from community mental health agencies, self-referrals, and referrals from other community members, with $69 \%$ of referrals coming from these sources in the new model compared with $58 \%$ in the old model. During the study time period, the new transitional case management service served 113 people; two thirds 
of the referrals came directly from the crisis service, and the remaining one third came from the inpatient services of local hospitals.

\section{Appropriateness of Crisis Service Patterns}

To evaluate the appropriateness of crisis service patterns, we examined two variables. First we considered the length of time individuals received crisis services, with an ideal maximum of 3 weeks. This was based on the assumption that a crisis is a serious situation, but by definition short-term and requiring immediate resolution. This assumption was consistent with Everly and Mitchell's (2000) conceptualization of a crisis as brief, typically requiring no more than three contacts. This does not negate the fact that people may benefit from longer periods of formal support for the problems they face, but only means that lengthy periods of service delivery are not consistent with the role of a crisis service. Comparisons of the two groups indicated that the new model was significantly more likely to service individuals within a 3-week time period, while more than half the clients of the old model were served for more than 3 months (see Table 2).

Table 2

Comparison of Length of Service in Old and New Models

\begin{tabular}{lccccc}
\hline $\begin{array}{l}\text { No. days of service } \\
\text { delivered }\end{array}$ & $\begin{array}{c}\text { Percentage } \\
\text { change }\end{array}$ & $\begin{array}{c}\text { OLD } \\
\text { MODEL } \\
\text { No. }\end{array}$ & $\begin{array}{c}\text { OLD } \\
\text { MODEL } \\
\%\end{array}$ & $\begin{array}{c}\text { NEW } \\
\text { MODEL } \\
\text { No. }\end{array}$ & $\begin{array}{c}\text { NEW } \\
\%\end{array}$ \\
\hline $1-21$ & 33 & 20 & 18.5 & 87 & 40.3 \\
$22-60$ & 39 & 20 & 18.5 & 99 & 45.8 \\
$61-90$ & 17 & 6 & 5.6 & 16 & 7.4 \\
91 or more & -8 & 62 & 57.4 & 14 & 6.5 \\
\hline
\end{tabular}

Note. Chi-squared $=0.000$.

The second variable we evaluated was exit disposition, assuming that given the changes and enhancements to the new service model, clients served would be significantly more likely to have an exit pattern that reflected resolution of services delivered. The results indicated that the new model was associated with significantly higher rates of completion of services, while the old model had higher rates of withdrawal from the service. In the new model, $85 \%$ of those receiving crisis services had their files closed as "complete" either with or without referral, compared with $29 \%$ in the old model.

\section{Acceptability of the New Crisis Service to the Local Service Network}

In total 24 surveys were completed by a range of community mental health and social services; a $44 \%$ response rate. This rate of return was lower than expected based on the assumption that there would be a sense of interdependence among community services in this small city centre. All of the surveys were completed by individuals with management responsibility. All but four of the services indicated that they were 
familiar with the new crisis model, and all indicated that they had made referrals to or served people who had used the crisis service.

The mean overall rating of satisfaction was 2.95 out of a possible 5.0, with ratings ranging from a high of 4.0 to a low of 1.83 . The police, hospitals, and community health agencies were the most satisfied with the new model (means ranging from 3.2-4.0), while non-health social services and educational institutions were the least satisfied (means ranging from 1.83-2.5). Table 3 provides mean satisfaction ratings for the main areas rated by the satisfaction survey, showing the different perceptions of the crisis service across service sectors.

Table 3

Means for Satisfaction Ratings by Service Sector (Total Possible Score = 5)

\begin{tabular}{|c|c|c|c|c|c|}
\hline & $\begin{array}{l}\text { Community } \\
\text { health service } \\
(n=6)\end{array}$ & $\begin{array}{c}\text { Hospital } \\
(n=6)\end{array}$ & $\begin{array}{l}\text { Police } \\
(n=1)\end{array}$ & $\begin{array}{c}\text { Education } \\
\text { institute } \\
(n=2)\end{array}$ & $\begin{array}{l}\text { Non-health } \\
\text { social service } \\
\quad(n=9)\end{array}$ \\
\hline The crisis service helps us do our jobs & 3.63 & 3.27 & 4.40 & 2.80 & 2.46 \\
\hline The crisis service is efficient & 4.20 & 3.33 & 4.00 & 2.93 & 3.13 \\
\hline $\begin{array}{l}\text { The crisis service meets the needs of } \\
\text { people with mental illness }\end{array}$ & 3.66 & 3.06 & 3.83 & 2.75 & 2.17 \\
\hline $\begin{array}{l}\text { Understanding of crisis service and } \\
\text { capacity to deal with crisis }\end{array}$ & 3.64 & 3.43 & 4.00 & 2.50 & 3.60 \\
\hline Overall rating of satisfaction & 4.00 & 3.17 & 4.00 & 2.50 & 1.83 \\
\hline Average & 3.85 & 3.28 & 4.03 & 2.73 & 2.88 \\
\hline
\end{tabular}

Table 4 provides information about the extent to which the crisis service was perceived to have improved on various elements of service delivery between 2004/05 and 2006/07. The greatest area of perceived improvement was accessibility. Community agencies perceived service capacity, mobile crisis response, and follow-up to be mostly the same or worse over the time period.

\section{Table 4}

Changes to Crisis Services as Perceived by Community Agencies (\% of Responses)

\begin{tabular}{lccr}
\hline & Improved & Same & Worse \\
\hline Accessibility & 45.0 & 55.0 & 0 \\
Service capacity & 26.3 & 57.9 & 15.8 \\
Service efficiency & 22.2 & 61.1 & 16.7 \\
Mobile crisis response & 38.9 & 55.6 & 5.6 \\
Referral to follow-up service & 11.8 & 70.6 & 17.6 \\
\hline
\end{tabular}


Qualitative comments on the surveys suggested recognition of many broader service-system issues constraining the work of the crisis service. These included the need for more crisis beds; more attention to the needs of people with addiction problems who also have psychosis; difficulties associated with individuals who refuse assistance; the need for more psychiatry services; and the need for more and better organized access to mental health resources in the community.

\section{DISCUSSION}

The evaluation presented in this paper provides evidence that a new integrated crisis-case management service led to expected changes in service utilization patterns. Specifically, the new model was associated with significantly greater service capacity, greater access to mobile crisis services, improvements in accessibility to crisis services across the broader community population, and crisis services that were briefer and more consistent with the theory of crisis as a time-limited experience. The findings related to acceptability of these new services to the local mental health and social service network suggested a diversity of perceptions about the crisis services offered across service sectors and a disconnect between these perceptions and actual shifts in service delivery patterns.

It is important to note that service utilization patterns do not reflect the quality of services offered, but rather whether the patterns of services provided are consistent with the expressed goals and objectives of the service. For example, this crisis service was interested in extending its reach to serve a broader range of crisis needs, beyond those experienced by people negotiating serious mental illness in their daily community life. Findings showed that individuals accessing the new model were more likely to be employed, to have fewer hospitalizations or emergency room visits in the months prior to crisis contact, and to access

crisis services through community referral sources. These findings suggest that a broader range of the public made use of these crisis services.

The model replicates the assertive delivery of mobile responses within a community-based crisis team. Unlike other services that describe their mobile capacity as a response to emergency calls, this mobile service was involved in assertively and routinely visiting community settings to raise the profile of the service and to avert crisis situations. While the results of this study indicated a dramatic increase in mobile responses by this crisis service, the nature of these services was not addressed within this study. In addition, routine processes for collecting data about individual contacts do not facilitate an understanding of these communitylevel strategies. The growing interest in developing crisis services that facilitate integration of responses to community crisis needs certainly speaks to the need to evolve a system to collect information about these types of community interactions. For example, Steadman and colleagues (2001) identify a set of principles that might be used to measure the impact of the collaboration between police and identified crisis response sites in meeting community crisis needs.

The findings of the present study suggest that the transitional case management program positively influenced the delivery of time-limited services consistent with the goal of the crisis service. Referrals to the TCM came from both the crisis service and the local inpatient psychiatric services. This study did not examine the nature of the services actually provided by the TCM, nor whether the program was able to 
address the needs of individuals within the expected 8- to 10-week time frame, but these questions are the subject of a study that is currently in progress.

The development of transitional case management services closely integrated with crisis services may have the potential to address gaps in the current mental health system. First, these services may provide a mechanism to recognize individuals who will benefit from longer term intensive community treatment, such as that offered by Assertive Community Treatment, while providing support and continuity of care until these services are accessed. One of the goals of the transitional case management service was to meet the transition needs of individuals leaving inpatient care, and from this perspective TCM has many similarities with the Critical Time Intervention described in the literature (Dixon et al., 2009). Second, TCM may provide a structure to support those with more moderate forms of mental illness whose needs have not been systematically addressed by mental health reform (Dewa, Rochefort, Rogers, \& Goering, 2003). A study focusing on the development of a competency profile of the transitional case management workers suggests that the work carried out by these case managers is distinct from both crisis work and more intensive and long-term case management (Krupa, Stewart, \& Mathany, 2009).

The survey on acceptance of the service by the local service network suggested that police, hospitals, and community health agencies have more favourable perceptions of the service than do social services or educational institutions. Certainly, the findings suggest that community outreach initiatives were more strategically oriented to developing collaborations with police and other health services compared to non-health social services and institutions. It may also be that the capacity of various service providers to respond to crises affected their rankings of the crisis service. For example, the higher rankings may have emerged from the capacity of those services to deliver a mental health crisis intervention when needed, by virtue of their trained staff, service missions, and structures. Non-health organizations on the other hand may be less resourced to deal with acute crises directly, and subsequently experience negative situations if there is any perceived failure in crisis service delivery. The findings certainly suggest the need for more follow-up with these services to understand their perspectives, to provide information about changes in service delivery, and to promote ongoing dialogue and problem-solving about emerging issues and challenges.

The study had several limitations. First, recruitment and hiring for all of the jobs within the new integrated crisis-case management service was not completed until November 2006; therefore the new model was not in full operation for the entire period of the study. The numbers of people served for both versions of the crisis service are underestimates, given that the nature of crisis services includes situations where crisis services are delivered but information about the individual is not provided, thereby preventing the creation of a unique client record. Comparisons of the two models were limited to data routinely collected and stored by the program; data were not specifically developed for this evaluation.

The study of two crisis services offered over different time periods must also be evaluated with the understanding that changes in the broader community may have influenced service delivery. For example, local changes that might have influenced patterns of service utilization included the development of early intervention for psychosis services and changes in referral structures for Assertive Community Treatment. 


\section{CONCLUSIONS}

This study presents the findings of an evaluation of a community-based crisis service that used systems enhancement funding to modify their services. The development of the new model of crisis service focused on increasing service capacity, access to mobile crisis response, and appropriateness of services delivered. Evaluation results indicate positive changes in the direction of desired service utilization patterns. The service model has potential to be relevant and generalizable to other communities. A particularly novel aspect of this new crisis service was the addition of a distinct, transitional case management service integrated with crisis services. This transitional case management program represented improvements in the capacity of the crisis service to provide needed follow-up services while maintaining the focus of crisis service delivery on shortterm intervention and meeting the broad spectrum of crisis needs in the community. Case management and crisis services have traditionally been considered distinct services, and funding models have not routinely supported the strategic and formal integration of these services. This service innovation supports the need for funding and service enhancement policies that are flexible and sensitive enough to address issues as they are emerging in the field and to promote innovation.

\section{RÉSUMÉ}

Dans cet article, nous présentons une évaluation des changements apportés aux services de crise en milieu communautaire à la suite de l'augmentation du financement du système de santé mentale. Nous montrons qu'il y a eu un accroissement des services de crise disponibles dans un délai plus adéquat, et que la mobilité des services s'est améliorée ; la recherche et des exemples de meilleures pratiques dans la littérature ont orienté ces améliorations. De plus, la gamme de services offerts s'est élargie pour permettre un meilleur suivi des patients ; dans le cas de cet objectif, il y avait peu d'outils pouvant servir de guides. Enfin, la création d'un modèle d'étude de cas temporaire intégrant les services de crise a constitué une innovation dans la prestation des services. Pour faire notre évaluation, nous avons utilisé des bases de données permettant de comparer la prestation des services de crise durant deux périodes ( « ancien modèle » vs « nouveau modèle »). Nous constatons que le nouveau modèle a effectivement permis les changements souhaités dans le modèle d'utilisation des services, en particulier en permettant d'augmenter les services, d'améliorer l'accès aux services (parce qu'ils sont plus mobiles), d'offrir des services dans des communautés plus importantes, et de créer des modèles de prestations de services plus adéquats (parce que les services de crise sont nécessaires moins longtemps, les mesures permettant la résolution des crises étant plus adéquates). Le degré d'acceptation de ces nouveaux services au niveau local a beaucoup varié selon les secteurs de services, ce qui suggère qu'il faut faire encore plus d'efforts au niveau du soutien en milieu communautaire. Nos observations montrent que les politiques et le financement du système de santé mentale doivent être flexibles pour pouvoir mieux s'adapter aux défis qui se présentent et faciliter l'innovation.

\section{REFERENCES}

Aguilera, D. (1998). Crisis intervention: Theory and methodology. St Louis: Mosby.

Bilsker, D., Moselle, K., Dick, A., Halpern, S., Havens, J., Lange, J., . . Jiwani, G. (2002). B.C. 's mental health reform best practices: Crisis response/emergency service. British Columbia: Ministry of Health and Ministry Responsible for Seniors.

Bonnie, R.J., Reinhard, J.S., Hamilton, P., \& McGarvey, E.L. (2009). Mental health system transformation after the Virginia Tech tragedy. Health Affairs, 28(3), 793-804.

Brown, J.F. (2005). Psychiatric emergency services: A review of the literature and a proposed research agenda. Psychiatric Quarterly, 76, 139-165. 


\section{AN EVALUATION OF A COMMUNITY-BASED, INTEGRATED CRISIS-CASE MANAGEMENT SERVICE}

Dewa, C., Rochefort, D.A., Rogers, J., \& Goering, P. (2003). Left behind by reform: The case for improving primary care and mental health system services for people with moderate mental illness. Applied Health Economics and Health Policy, 2, 43-54.

Dixon, L., Goldberg, R., Iannone, V., Lucksted, A., Brown, C., Kreyenbuhl, J., . . Potts, W. (2009). Use of a critical time intervention to promote continuity of care after psychiatric inpatient hospitalization. Psychiatric Services, $60,451-458$.

Everly, G.S., \& Mitchell, J.T. (2000). The debriefing controversy and crisis intervention: A review of lexical and substantive issues. International Journal of Emergency Mental Health, 2(4), 211-225.

Ferris, L.E., De Siato, C., Sandercock, J., Williams, J.I., \& Shulman, K.I. (2003). A descriptive analysis of two mobile crisis programs for clients with severe mental illness. Canadian Journal of Public Health, 94, 233-237.

Geller, J.L., Fisher, W.H., \& McDermeit, M. (1995). A national survey of mobile crisis services and their evaluation. Psychiatric Services, 46, 893-897.

Guo, S., Biegel, D.E., Johnsen, J.A., \& Dyches, H. (2001). Assessing the impact of community-based mobile crisis services on preventing hospitalization. Psychiatric Services, 52, 223-228.

Health Systems Research Unit. (1997). Best practices in mental health reform: Discussion paper. Ottawa, ON: Federal/ Provincial/Territorial Advisory Network on Mental Health.

Johnson, S. (2004). Crisis resolution and intensive home treatment teams. Psychiatry, 3, 22-25.

Joy, C.B., Adams, C.E., \& Rice, K. (2006). Crisis intervention for people with severe mental illness. Cochrane Database of Systematic Reviews, (4).

Kaplan, R., \& Norton, D.P. (1996). The balanced scorecard: Translating strategy into action. Boston: Harvard Business School Press.

Krupa, T., Stuart, H., \& Mathany, A. (2009). An evaluation of an integrated crisis-case management service. Toronto, ON: Systems Enhancement Evaluation Initiative. Retrieved from https://ozone.scholarsportal.info/ bitstream/1873/15233/1/294294.pdf

Lamb, R., Weinberger, L.E., \& DeCuir, W.J. (2002). The police and mental health. Psychiatric Services, 53, 1266-1271.

Lauer, M., \& Brownstein, R. (2008). Replacing the revolving door: A collaborative approach to treating individuals in crisis. Journal of Psychosocial Nursing and Mental Health Services, 46(6), 25-33.

Ligon, J. (2005). Mobile crisis units: Frontline community mental health services. In A.R. Roberts (Ed.), Crisis intervention handbook: Assessment, treatment and research. New York: Oxford University Press.

Mental Health Commission of Canada. (2009). Toward recovery \& well-being: A framework for a mental health strategy for Canada. Retrieved from http://www.mentalhealthcommission.ca/English/Pages/Strategy.aspx

Ontario Ministry of Health and Long-Term Care. (2005). Crisis response service standards for mental health services and supports. Retrieved from www.health.gov.on.ca/english/public/pub/ministry_reports/mentalhealth/cris_resp

Public Health Agency of Canada. (2002). Review of best practice in mental health reform. Ottawa: Author.

Sartorius, N. (2002). Iatrogenic stigma of mental illness begins with behaviour and attitudes of medical professionals, especially psychiatrists. British Medical Journal, 324, 147-149.

Scott, R.L. (2000). Evaluation of a mobile crisis program: Effectiveness, efficiency and consumer satisfaction. Psychiatric Services, 51, 1153-1156.

Steadman, H.J., Stainbrook, K.A., Griffin, P., Raine, J., Dupont, R., \& Horey, C. (2001). A specialized crisis response site as a core element of police-based diversion programs. Psychiatric Services, 52, $219-222$. 
